\title{
Examining Tripleurospermum inodorum (Scentless Mayweed) (Asteraceae) inland
}

\author{
Michael Wilcox \\ Bradford, West Yorkshire, UK
}

\section{Corresponding author: michaelpw22@hotmail.com}

This pdf constitutes the Version of Record published on $28^{\text {th }}$ February 2022

\begin{abstract}
A recently-published paper on Tripleurospermum (Asteraceae) gave the impetus to examine a small population of this genus on waste ground in Bradford (v.c.63). A few of the plants appeared to be T. inodorum (L.) Sch. Bip. (Scentless Mayweed) but the others had features of both this species and T. maritimum (L.) W.D.J. Koch (Sea Mayweed), suggesting the hybrid T. inodorum x T. maritimum. This supports the occurrence of the hybrid at inland sites, where any backcrossing and further introgression would mainly be with $T$. inodorum. In addition, the presence of pure $T$. maritimum at inland localities cannot be ruled out (perhaps as a halophyte). Such findings reinforce the importance of careful examination of both inland and coastal populations.
\end{abstract}

Keywords: mature achenes; oil glands; hybridisation; introgression; dispersal mechanisms

\section{Introduction}

The features that distinguish Tripleurospermum inodorum (L.) Sch. Bip. (Scentless Mayweed) from T. maritimum (L.) W.D.J. Koch (Sea Mayweed) are largely those of the mature achenes (Stace, 2019). The main difference is in the shape of the subapical oil glands on one face, and the thickness of the ribs and the width of the spaces between them on the other face. There are also slight differences in size, though both characters vary a little between authors. This variation is summarised in Table 1 based on Stace (2019) and the most recent study of the genus by Crossley et al. (2021). Only mature well-formed achenes (for example like those shown in Figs. 1 and 2) should be used to form a diagnosis.

Table 1. Characteristics of achenes of Tripleurospermum maritimum and $T$. inodorum from two sources.

\begin{tabular}{|l|l|l|l|}
\hline Character & T. maritimum & T. inodorum & Author(s) \\
\hline Oil glands & Distinctly elongated & Orbicular to angular & Stace (2019) \\
\hline & Oblong & More or less round & Crossley et al. (2021) \\
\hline Achenes & $1.8-3.5(4) \mathrm{mm}$ & $1.3-3 \mathrm{~mm}$ & Stace (2019) \\
\hline & $2-3$ or $2.5-3.5 \mathrm{~mm}$ & $1.5-2.2 \mathrm{~mm}$ & Crossley et al. (2021) \\
\hline
\end{tabular}

Tripleurospermum maritimum is said to be (biennial to) perennial and $T$. inodorum annual; the leaves of T. maritimum are stated to be fleshy (succulent) and 
(acute to) obtuse-rounded, whereas those of T. inodorum are not succulent and acute to often bristle-tipped (Stace, 2019). In their typical state the two taxa appear to be good species. Some of the overlap in all characters of these taxa may be due to hybridisation and introgression and this may have blurred the distinction between the two species over time.

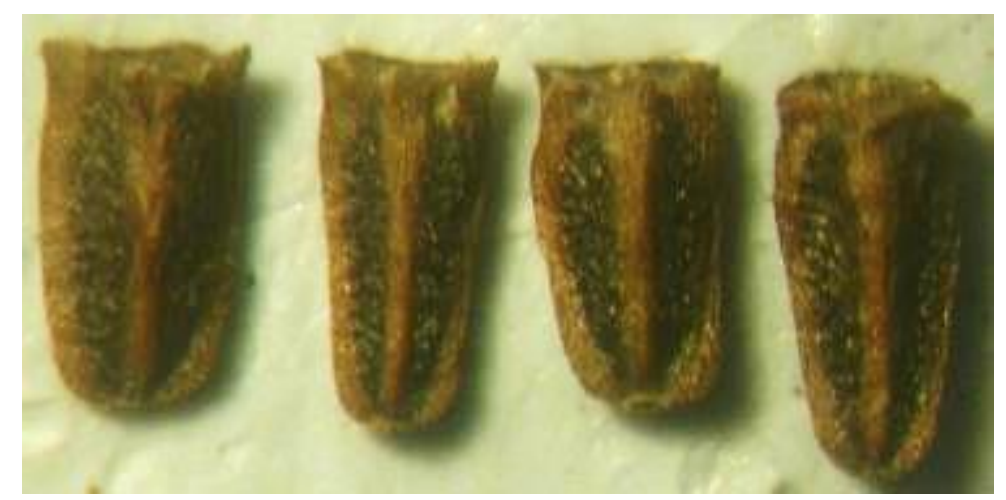

Figure 1. Achenes of Tripleurospermum inodorum (from waste ground of Skelton services: SE35183100, v.c.64. 09.10.2021). Average size of 10 achenes was $1.6 \mathrm{x}$ $0.75 \mathrm{~mm}$. The width of the dark brown areas between ribs is \pm greater than the width of the narrow ribs. All the oil glands were small and distinctly rounded.
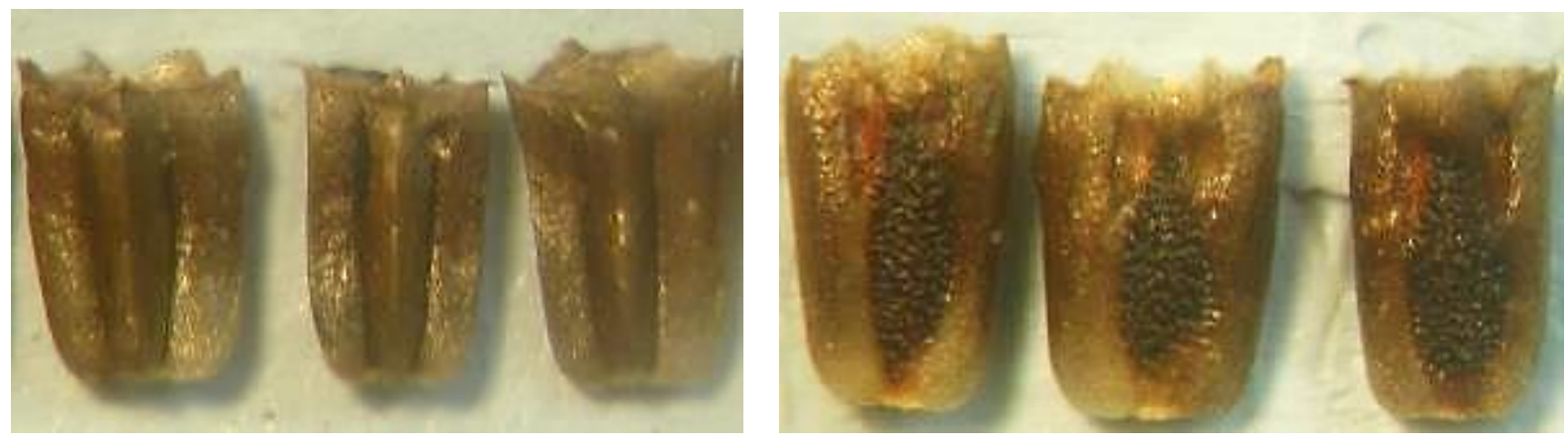

Figure 2. Achenes of Tripleurospermum maritimum (from Hightown, strandline SD296027, v.c.59, 10.10.21). Adaxially (left) there is virtually no gap between the thickened ribs. Abaxial view (right) shows the more elongated oil glands on the back. The average size of 20 mature achenes was $3 \times 1.85 \mathrm{~mm}$. (Achenes courtesy of Phil Smith).

\section{Current study}

Tripleurospermum maritimum is most likely to be found on or very near the coast. However, there is a possibility that this taxon and the hybrid could make their way inland along salt-treated roads, occurring as halophytes. This may be one route promoting hybridisation and subsequent introgression. The buoyant achenes (particularly of T. maritimum and the hybrid) make rivers another possible route for dispersal inland enabling introgression with inland $T$. inodorum.

In Bradford (v.c.63; S.W. Yorkshire), an area far inland from any coastline, one might expect to find only $T$. inodorum. The current study site off Romanby Shaw, (SE18983683) was disturbed when some houses were built and the fences surrounding the local swimming baths were removed to gain (pedestrian) access. Following the disturbance, at least 110 plant taxa have been recorded so far. Two of these were new records for hectad SE13: Coreopsis tinctoria Nutt. (Golden Tickseed 
- three plants only), and Salvia viridis L. (Annual Clary - two small plants resembling the cultivar 'Pink Sundae'). At least 20 plants of Tripleurospermum occurred in a small patch $(15 \times 20 \mathrm{~m})$, and two or more plants of Matricaria chamomilla L. (Scented Mayweed) were also present. Six plants of Tripleurospermum were collected for this study.

One of the six plants was similar to $T$. inodorum in its features. It matched that shown in Fig 1c \& d in Crossley et al. (2021) (taken from Fig. 1 in Skilbeck et al., 2019) in having more or less small round subapical oil glands on one face and the relatively narrow ribs on the other face with the brown granular spaces between them being mainly wider than the width of the ribs. The other five plants collected were 'intermediate' (a loose term) between T. inodorum and T. maritimum. Details of 10 achenes from one of these intermediates are given in Table 2. Two of these achenes are illustrated in Fig. 3.

Table 2. Measurements of 10 achenes from an intermediate plant at the study site. Achenes marked as * are shown in Fig. 3.

\begin{tabular}{|c|c|c|c|c|}
\hline Achene & $\begin{array}{c}\text { Length } \\
\mathrm{mm}\end{array}$ & $\begin{array}{l}\text { Width } \\
\mathrm{mm}\end{array}$ & Oil gland & Comment on oil gland \\
\hline 1 & 2.35 & 1.30 & Ovate & Almost round \\
\hline 2* & 2.60 & 1.50 & $\begin{array}{l}\text { Long-ovate } 0.7 \times 0.3 \\
\mathrm{~mm}\end{array}$ & Longer than wide \\
\hline 3 & 2.50 & 1.20 & Large ovate & Large but still oval in shape \\
\hline 4 & 2.50 & 1.10 & Ovate & Almost round \\
\hline 5 & 2.50 & 1.10 & Ovate & Almost round \\
\hline 6 & 2.70 & 1.40 & Long-ovate & Longer than wide \\
\hline 7* & 2.65 & 1.30 & $\begin{array}{l}\text { Distinctly long } 1.9 \mathrm{x} \\
0.35 \mathrm{~mm}\end{array}$ & Much longer than wide \\
\hline 8 & 2.50 & 1.35 & Ovate-distorted & $\begin{array}{l}\text { Distorted some ribs forming on } \\
\text { face }\end{array}$ \\
\hline 9 & 2.80 & 1.50 & Ovate-distorted & $\begin{array}{l}\text { Distorted some ribs forming on } \\
\text { face }\end{array}$ \\
\hline 10 & 2.50 & 1.30 & Ovate & Oval - generally roundish \\
\hline
\end{tabular}

In general, the oil glands were almost round to some more elongated, to two being longer than wide (achenes 2 and 7) but still large with rounded ends (Fig. 3). Other oil glands in this plant varied from almost round to slightly elongate (oval). In some of the other plants many had rounded oil glands but show the thick ribs with varied narrow spaces between them.

The achenes of a third plant from Bradford (Fig. 4) clearly show the relatively thick ribs with the 'brown-granular' spaces between them much narrower than the rib thickness. These could feasibly be called $T$. maritimum except that the oil glands were more round to oval and rarely elongated as in Fig. 3. Plants having achenes with thick ribs, with variable bowed-to-linear spaces between them (i.e. often asymmetrical, being wider on one side than the other) and variable oil gland shape, suggest they belong to the hybrid between the two taxa. Fig. 5 shows a direct comparison of size and the type of rib and the spacing (or lack of) between pure plants from Skelton (Fig. 1) and Hightown (Fig. 2) and a putative hybrid from Bradford. 

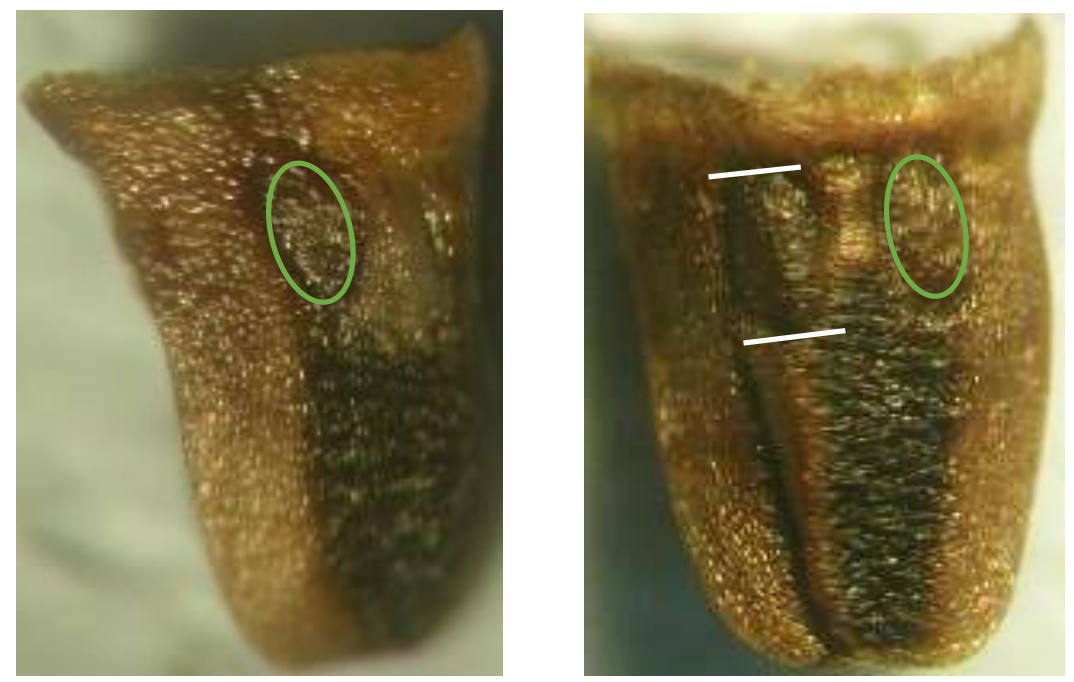

Figure 3. Left: achene number 2 from Table 2 (one gland shown, outlined in green). Right: achene number 7 - the shorter of the two glands on the right of the achene has been outlined in green to show the more elongate shape; the one on the left is a bit longer and the length is highlighted by the white lines. Note the thick ribs even on the abaxial surface.

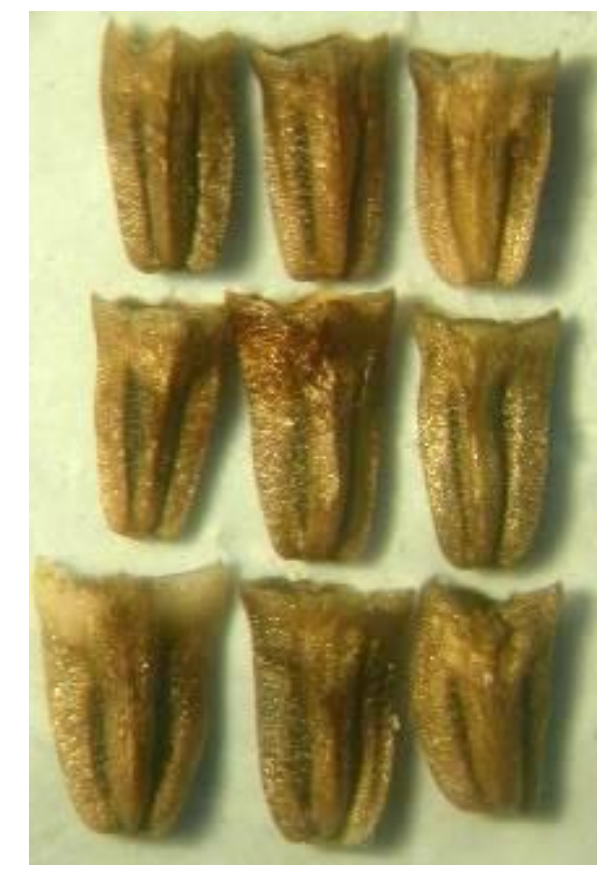

Figure 4. Achenes of a second intermediate plant from the study site.

The phyllaries of putative hybrids from Bradford did not seem that different to those of pure T. inodorum from Skelton services (Fig. 1). Thus the phyllaries (at least in this study) seemed to offer little scope for distinguishing the two species or hybrids (but see Crossley et al., 2021). Introgression is likely to blur any distinction further.

Similarly, the leaves of the putative hybrid plants at the study site have leaf segments with more or less obtuse apices with a small apiculus at the tip, though 
some had more acute apices with a longer apiculus but they were generally obtuse and not fleshy. If $T$. maritimum has the blunter leaf segments, then the putative hybrid plants from Bradford clearly show aspects of that taxon. In fact, with the achene characters and the type of leaf-tips it suggests the Bradford plants (rather than being fully intermediate) are closer to T. maritimum than T. inodorum.

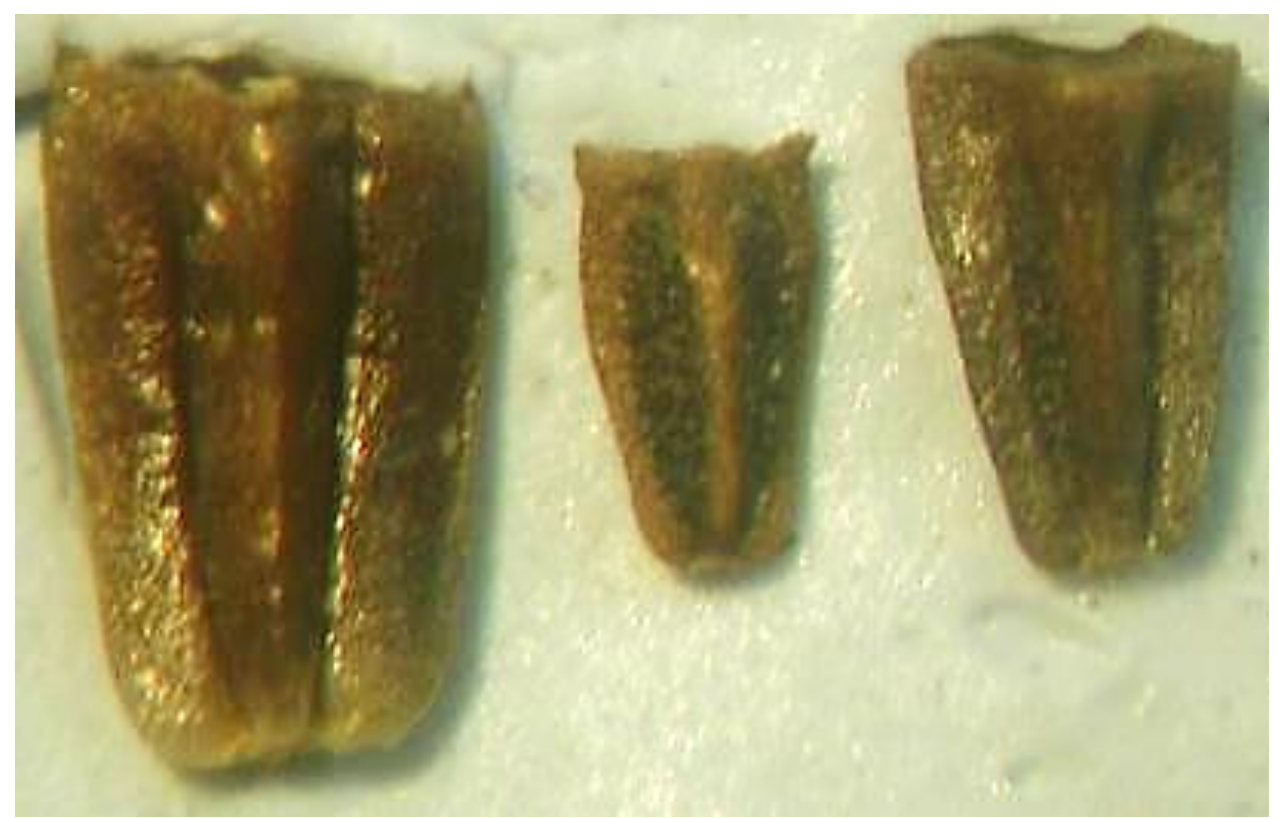

Figure 5. A direct comparison of achenes from the three Tripleurospermum taxa: T. maritimum from Hightown (left, actual size: $3.2 \times 1.85 \mathrm{~mm}$ ), $T$. inodorum from Skelton (middle), and a putative hybrid from Bradford (right). In the latter note the thickened ribs and offset spacing between them.

\section{Fertility}

In relation to fertility, it is difficult to assess the level of sterility (infertility) from achenes, and whether this is related to hybridisation or self-incompatibility (requiring cross pollination) or other factors is unknown. Some of the plants in Bradford have relatively short broad achenes but with thick ribs and variable spaces between them, but in the same head they have many pale poorly developed achenes (Fig. 6). In the right-hand image of Fig. 6, the average size of achenes in the top row is $2.2 \times 1.1$ $\mathrm{mm}$ and for those in the bottom row is $1.9 \times 0.55 \mathrm{~mm}$. It can be seen that the ribs are variably thickened with spaces similar to or obviously narrower than their thickness. This is the same in the sterile achenes with narrow linear spaces between, but in that case it could be to do with the lack of development (see Skilbeck et al., 2019). These are clearly not assignable to pure $T$. inodorum and would at least be loosely considered as intermediate.

Although fertility relating to pollen was not studied in detail, it was noted that the size of the pollen grains was very variable and while appearing round and not (empty) sterile, they may have been incapable of fertilising the ovaries. However, in a putative hybrid from Bradford the variable pollen size was similar to $T$. inodorum itself, suggesting that pollen may not be a useful factor in determining this hybrid. Thus, neither lack of achene development or pollen fertility seems useful in determining hybrids. Another factor is that often the inside of the dome-shaped receptacle has a 'grub' inside, which may affect the development. 

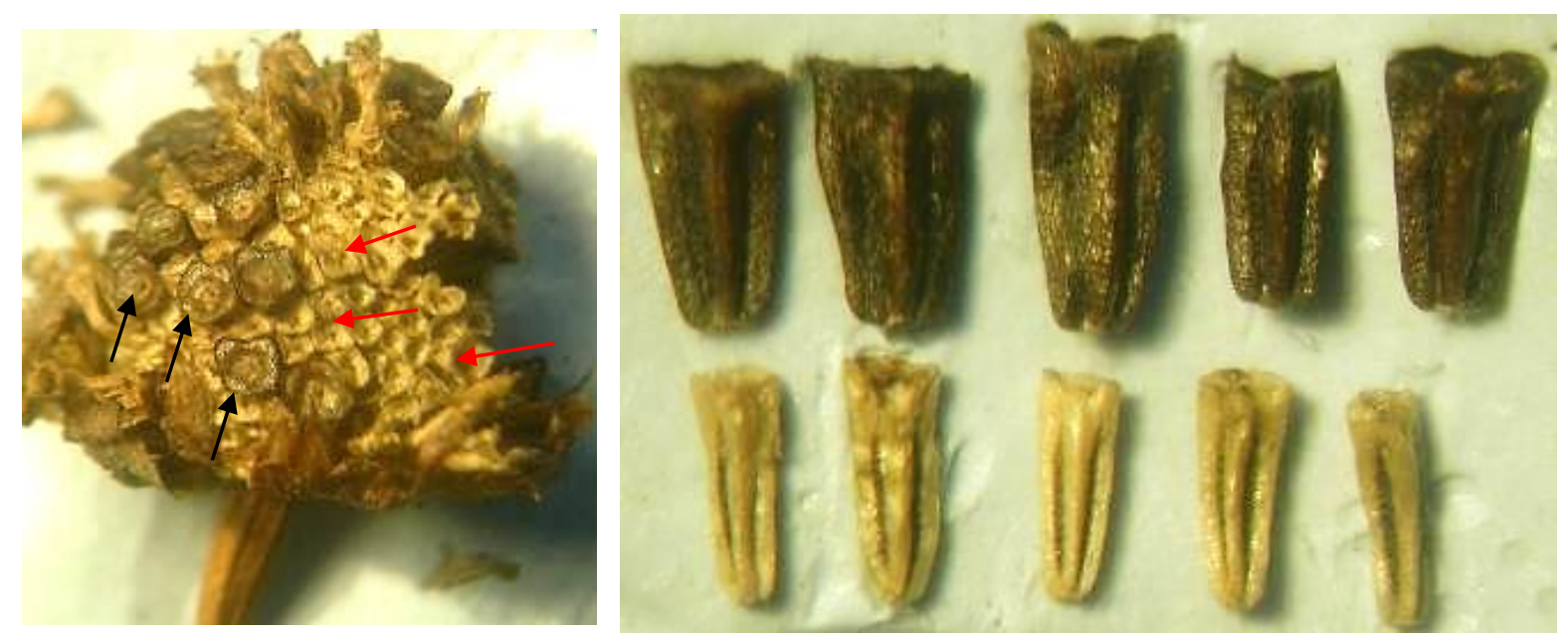

Figure 6. Achenes from intermediate plants at the study site. Left: flowerhead with three of the mature achenes arrowed in black and all of these stand proud of the pale (sterile?) ones, of which some are arrowed in red. Right: five of these mature achenes in the top row and five of the more infertile looking ones in the bottom row.

\section{Concluding remarks}

Based on the achenes and oil gland characters generally adopted to distinguish $T$. inodorum from $T$. maritimum, there is strong evidence for regarding the plants with intermediate characters at the Bradford site either as true hybrids or as the product of introgression, perhaps with a bias towards T. maritimum in some features like the thicker ribs. For T. maritimum achenes were received from two sources, the Sefton Coast and Lincolnshire. Only those from the Sefton Coast were used for comparison in this study as those from Lincolnshire were deemed to be a backcross. Routes of dispersal for T. maritimum including road-salting and watercourses increase the likelihood of finding hybrids and even pure T. maritimum at inland sites that have traditionally been considered to be the domain of only $T$. inodorum. This supports the observations of Crossley et al. (2021) showing that despite clear morphological separation of the two main taxa, there is a blurring of the two to some extent suggesting introgression may be frequent in certain habitats. The size of achenes and rib type may be important in combination with other characters. T. inodorum has the smallest achenes $(\leq 2(2.2) \times 1(1.2) \mathrm{mm})$ with narrow, (not thickened) ribs; T. maritimum has the largest $(\geq(2.5) 3-4 \times(1.3) 1.5-2 \mathrm{~mm})$, with distinctly thickened ribs, and hybrids appear to be variously intermediate in terms of oil gland shape and spacing between the ribs (which tend to be thickened).

Close scrutiny is clearly needed of both inland plants and coastal plants of Tripleurospermum. Though T. inodorum is common and likely to be found easily, and the site in Bradford is only a single incidence for the time being, it may not be atypical, thus making it more difficult to record $T$. inodorum than expected. With more diligent recording, all three taxa might increasingly be found inland in the future. However, molecular work might be an advisable next step to understanding the systematics of the two species more clearly and in turn identifying the extent and distribution of hybridisation and levels of introgression. 


\section{Acknowledgements}

I would like to thank Chris Skilbeck for looking at some achenes and agreeing that the Bradford plants were in the range of the hybrid and for related discussion, Phil Smith for the distinctive T. maritimum achenes from the Sefton Coast, Paul Kirby for material from Lincolnshire and Ian Denholm for comments on the manuscript.

\section{References}

Crossley, J. \& Skilbeck, C.A. 2021. Sea Mayweed Tripleurospermum maritimum and Scentless Mayweed T. inodorum (Asteraceae) intermediates in Orkney. British \& Irish Botany 3(3): 297-323. https://doi.org/10.33928/bib.2021.03.297

Skilbeck, C.A., Lynch, I., Ellenby, M. \& Spencer, M.A. 2019. Achene Morphology of British and Irish Mayweeds and Chamomiles: implications for taxonomy and identification. British \& Irish Botany. 1(2): 128-166. https://doi.org/10.33928/bib.2019.01.128

Stace, C.A. 2019. New Flora of the British Isles. $4^{\text {th }}$. ed. Middlewood Green, Suffolk: C \& M Floristics.

Copyright retained by author(s). Published by BSBI under the terms of the Creative Commons Attribution 4.0 International Public License.

ISSN: $2632-4970$

https://doi.org/10.33928/bib.2022.04.051 